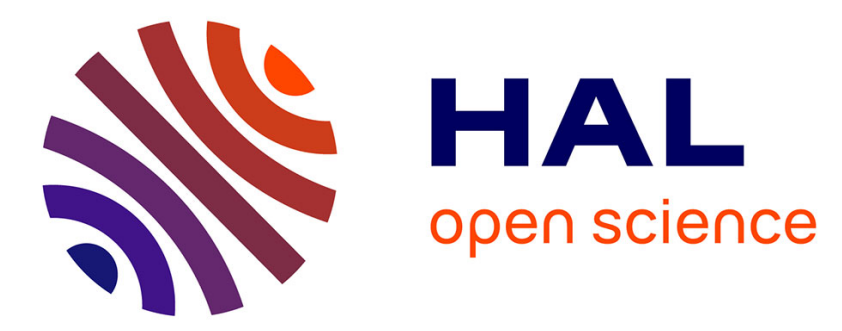

\title{
Modelling of corrosion fatigue crack initiation on martensitic stainless steel in high cycle fatigue regime
}

Mohamed El May, Mohamed El May, Nicolas Saintier, Thierry Palin-Luc, Olivier Devos, Olivier Brucelle

\section{- To cite this version:}

Mohamed El May, Mohamed El May, Nicolas Saintier, Thierry Palin-Luc, Olivier Devos, et al.. Modelling of corrosion fatigue crack initiation on martensitic stainless steel in high cycle fatigue regime. Corrosion Science, 2018, 133, pp.397-405. 10.1016/j.corsci.2018.01.034 . hal-01812623

\section{HAL Id: hal-01812623 https://hal.science/hal-01812623}

Submitted on 19 Dec 2018

HAL is a multi-disciplinary open access archive for the deposit and dissemination of scientific research documents, whether they are published or not. The documents may come from teaching and research institutions in France or abroad, or from public or private research centers.
L'archive ouverte pluridisciplinaire HAL, est destinée au dépôt et à la diffusion de documents scientifiques de niveau recherche, publiés ou non, émanant des établissements d'enseignement et de recherche français ou étrangers, des laboratoires publics ou privés. 


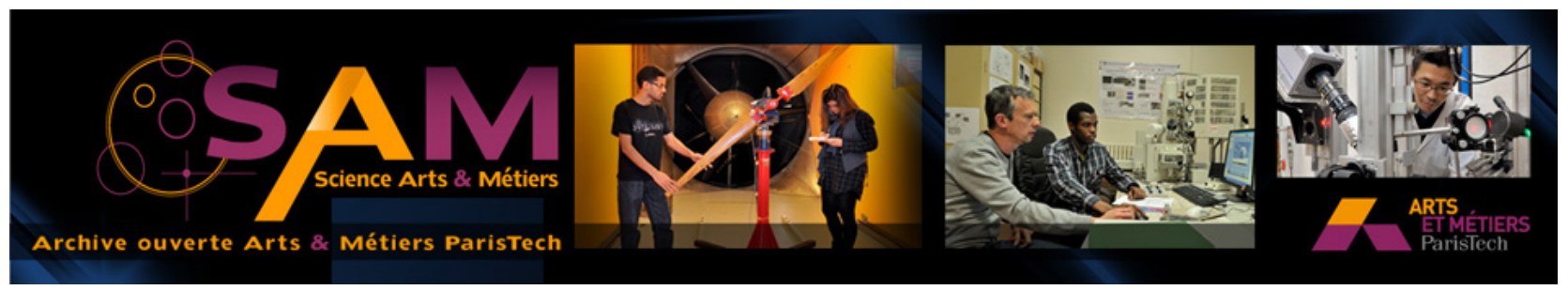

Science Arts \& Métiers (SAM)

is an open access repository that collects the work of Arts et Métiers ParisTech researchers and makes it freely available over the web where possible.

This is an author-deposited version published in: http://sam.ensam.eu Handle ID: .http://hdl.handle.net/null

\section{To cite this version :}

Mohamed EL MAY, Nicolas SAINTIER, Thierry PALIN-LUC, Olivier DEVOS, Olivier BRUCELLE Modelling of corrosion fatigue crack initiation on martensitic stainless steel in high cycle fatigue regime - Corrosion science - Vol. 133, p.397-405 - 2018 


\title{
Corrosion Science
}

\section{Modelling of corrosion fatigue crack initiation on martensitic stainless steel in high cycle fatigue regime}

\author{
Mohamed El May ${ }^{\mathrm{a}, *}$, Nicolas Saintier ${ }^{\mathrm{a}}$, Thierry Palin-Luc ${ }^{\mathrm{a}}$, Olivier Devos ${ }^{\mathrm{b}}$, Olivier Brucelle \\ a Arts et Metiers ParisTech, I2M Bordeaux, CNRS, 33405 Talence, France \\ ${ }^{\mathrm{b}}$ Universite Bordeaux, I2M Bordeaux, CNRS, 33405 Talence, France \\ ${ }^{\mathrm{c}}$ UTC Aerospace Systems, Ratier-Figeac, 46100 Figeac, France
}

\begin{abstract}
A B S T R A C T
This paper presents an analytical model for assessing the corrosion fatigue crack initiation life on a martensitic stainless steel X12CrNiMoV12-3 in high cycle fatigue regime (between $10^{5}$ and $10^{7}$ cycles). Based on in-situ electrochemical measurements during corrosion fatigue tests in $\mathrm{NaCl}$ aqueous solution, the corrosion fatigue crack initiation mechanism was identified. Two main stages were investigated: (i) the fracture of the passive film by slip bands and (ii) the free dissolution of the metal developing fatigue crack initiation from a critical corrosion defect. The depassivation stress threshold corresponds to the median fatigue strength at $10^{7}$ cycles for fatigue corrosion tests. For an applied stress range less than this threshold, the depassivation phenomenon was not observed at $10^{7}$ cycles and no crack initiation occurred. The proposed model takes into account the depassivation process induced by the slip bands emergence at the specimen surface and the corrosion rate under cyclic loading. The experimental results are compared to the proposed model taking into account mechanical and electrochemical material parameters.
\end{abstract}

\section{Introduction}

The practical importance of fatigue failure in structural materials has motivated many works towards assessing the physical reasons for material sensitivity to corrosion fatigue $(\mathrm{CF})$ and providing adequate damage models for engineers. In particular, developing an analytical methodology for predicting corrosion fatigue crack initiation (CFCI) [1-8] and corrosion fatigue crack growth $[7,9,10]$ for structures is a key issue. A model to compute the fatigue life of material (to crack initiation) under corrosion fatigue should takes many variables into consideration: chemical nature of the environment, stress/strain levels, stress ratio and loading frequency. Most investigators agree that CFCI occurs at the surface around corrosion defects [11-14]. The effect of corrosion on fatigue life of stainless steels is most closely related to the passive film resistance $[11,15]$. Much study has been focused on the effect of the microstructure, the thickness and the chemical composition of the passive films, on corrosion behaviour of metallic alloys, using surface analyses techniques [16-18]. But the mechanical behaviour of passive layer (thickness lower than $10 \mathrm{~nm}$ ) stay to be difficult to characterise experimentally.

Several CFCI models were proposed and can be classified into:
1. competition between pit growth and short crack propagation $[1,2]$,

2. preferential dissolution of plastically deformed material $[3,19,20,8,14]$,

3. local rupture of the passive film by slip bands [4-6,21-24] and

4. lowering of surface energy due to adsorption of specific species from the environment [7].

All of the above mechanisms involve a synergetic contribution of mechanical loading and electrochemical behaviour of tested material. In order to accurately predict the CFCI life, it is necessary to consider synergetic effects between cyclic loading (stress level, load ratio, loading frequency), material (passive layer) and corrosion parameters $[22,12,15,8]$. Recent advances in local electrochemical characterization techniques have allowed to develop research works at the microscopic scale [25]. These techniques are used in stress corrosion cracking (SCC) tests to capture, in-situ, the temporal electrochemical behaviour $[26,27]$. Experimental evidence show that pit growth rate is influenced by static stress in SCC tests $[28,27,29]$ and by cyclic stress $[6,30,31]$. In HCF tests, the magnitude of synergetic effects is of major influence the pit initiation (depassivation) stage. This phenomenon can be evaluated by the use of in-situ global free potential measurement during $\mathrm{CF}$ test $[32,11,33]$. That allows to characterize the depassivation and corrosion 


\section{Nomenclature}

AES Auger electron spectroscopy

HCF high cycle fatigue

CFCI corrosion fatigue crack initiation

$\mathrm{CF} \quad$ corrosion fatigue

PSB persistent slip band

$N_{\mathrm{f}} \quad$ number of cycles to fatigue crack initiation

$N_{\mathrm{d}} \quad$ number of cycles to depassivation

$N_{\text {c }} \quad$ number of cycles to develop a corrosion critical defect with regard to fatigue crack initiation

$R \quad$ loading ratio

$f \quad$ loading frequency

$\Delta \sigma \quad$ stress range: $\Delta \sigma=\sigma_{\max }-\sigma_{\min }$

$\Delta \sigma_{\text {th }} \quad$ threshold value of $\Delta \sigma$ for depassivation

$\Delta \sigma_{\text {eff }} \quad$ effective stress range: $\Delta \sigma_{\text {eff }}=\Delta \sigma-\Delta \sigma_{\text {th }}$
$\Delta \varepsilon^{\mathrm{p}}$

$\sqrt{\text { area }}$

SCE

$E_{\text {free }}$

$I_{\text {corr }}$

$i_{\text {corr }}$

$\mathrm{A}_{\mathrm{s}}$

$\rho$

F

$M$

$\delta_{\mathrm{s}}$

$h_{\mathrm{s}}$

b

$e$ plastic strain range: $\Delta \varepsilon^{\mathrm{p}}=\Delta \varepsilon_{\max }^{\mathrm{p}}-\Delta \varepsilon_{\min }^{\mathrm{p}}$ square root area of the defect projected onto a plane perpendicular to the maximum normal stress saturated calomel electrode

free electrochemical potential

current value achieved during activated corrosion period $\left(N>N_{\mathrm{d}}\right)$

current density, the exposed surface is $1 \mathrm{~cm}^{2}$

aqueous solution with $0.1 \mathrm{M} \mathrm{NaCl}$ and $0.044 \mathrm{M} \mathrm{Na}_{2} \mathrm{SO}_{4}$

volumetric mass

Faraday constant

molar mass

slip band height

slip band spacing

burgers vector

corrosion defect thickness activity at the surface of the specimen during cyclic loading.

In the case of stainless steels, CF crack initiation is promoted by cyclic mechanical damage of the protective passive layer induced by the emergence of slip band. Passive films can act as obstacles to dislocation activity $[21,15]$. Consequently, the PSB spacing will be small because slip localization is inhibited [34,35]. By raising the dissolution rate, or by making the oxide film thinner, the barriers to slip are reduced, slip localization is favoured and PSB spacing increases [22]. The matrix dislocations tends to be transferred more easily into the PSB, further accelerating the formation of PSBs causing local ruptures of the passive layer [34]. Once the passive film damaged, the metal is directly exposed to the aqueous environment, resulting in preferential anodic area for local corrosive dissolution. This results in geometric corrosion defects leading to corrosion fatigue crack initiation $[36,37,13]$. The stress intensity will become high enough to initiate a crack in the metal $[38,14,8]$. An important requirement for this crack initiation scenario is that the material, in the given aqueous environment, must be in the passive domain without any cyclic loading. An efficient way to monitor passive film failure is to perform in-situ measurements of the free potential. Previous studies have shown that a sudden drop in the potential occurs when the mechanical cyclic loading (fatigue) is applied to the material [11]. When considering the CF processes on stainless steel, it should be noticed that both characteristic times of the cyclic loading and passivation processes influence the overall mechanical-corrosion synergetic effects. Indeed, if the passivation process occurs at a higher rate than the mechanically induced passive film damage, no CF effect is expected. On the contrary if the passivation process is too slow, localized dissolution process can take place leading to fatigue crack initiation.

In this study we investigated the effect of aqueous corrosion $(0.1 \mathrm{M}$ $\mathrm{NaCl}+0.044 \mathrm{M} \mathrm{Na}_{2} \mathrm{SO}_{4}$ ) on the CFCI mechanism of a martensitic stainless steel X12CrNiMoV12-3 used for aeronautical applications. An analytical CFCI model is proposed considering the coupling between corrosion parameters and cyclic loading in the HCF regime.

\section{Material and methods}

\subsection{Material}

The material used in this study is a martensitic stainless steel X12CrNiMoV12-3 used in aeronautical structures. The chemical composition of this alloy, in weight percent, is given as follows: $0.12 \mathrm{C}$, $12 \mathrm{Cr}, 3 \mathrm{Ni}, 1.6 \mathrm{Mo}, 0.3 \mathrm{~V}$ and Fe balance. Microstructural investigations showed a typical equiaxed martensite lath structure with residual austenite (less than $1 \%$ in the volume). The martensite lath dimension is around $2-3 \mu \mathrm{m}$. Prior austenite average grain dimension is around $100 \mu \mathrm{m}$. The $0.2 \%$ offset yield strength, and elongation to failure of the alloy are $1040 \mathrm{MPa}$ and $15 \%$ respectively.

\subsection{Experimental methods}

For crack nucleation tests, $8 \mathrm{~mm}$ cylindrical specimens were machined from rolled bar and mechanically polished to obtain a surface finish with arithmetic roughness of about $0.1 \mu \mathrm{m}$. Uniaxial fatigue tests were performed under load control, using a resonant electromagnetic fatigue testing machine at $120 \mathrm{~Hz}$ (Vibrophore type). This frequency was chosen so that failure between $10^{5}$ and $10^{7}$ cycles could be reached in a reasonable testing time. Moreover, this loading frequency is typical for HCF test, even if it is higher than what is usually used for corrosion fatigue studies [32]. The stop criterion was a loading frequency drop of $0.7 \mathrm{~Hz}$, corresponding to a technical fatigue crack with a typical surface length of $5 \mathrm{~mm}$ and a depth of $2 \mathrm{~mm}$. In order to investigate a possible frequency effect, additional $\mathrm{CF}$ tests were performed at $10 \mathrm{~Hz}$ on a servo-hydraulic fatigue testing machine.

$\mathrm{CF}$ testing were carried out at room temperature $\left(\simeq 20^{\circ} \mathrm{C}\right)$ under an aerated $0.1 \mathrm{M} \mathrm{NaCl}$ and $0.044 \mathrm{M} \mathrm{Na}_{2} \mathrm{SO}_{4}$ aqueous solution $\left(\mathrm{A}_{\mathrm{s}}\right)$ (with $p H \simeq 6$ and $\left[\mathrm{O}_{2}\right] \simeq 7 \mathrm{ppm}$ ) at the free potential. This aqueous media was optimized to reproduce the same morphology of corrosion defect observed at the surface of real components using a thin-layer cell [39]. The addition of sulphate limited the increase of the anodic potentials with the inhibitive effect of $\mathrm{SO}_{4}^{2-}$ anion on pitting corrosion $[17,40]$. To perform corrosion fatigue tests in the passive domain of the tested material, the $\left(A_{s}\right)$ aqueous solution was selected. In this case, the prospective depassivation and pitting of the material under cyclic loading (fatigue test) is stress-assisted mechanisms. An electrochemical corrosion cell was developed for corrosion fatigue tests. This cell allows insitu fatigue testing in an aqueous corrosive environment and include three electrodes: a saturated calomel electrode (SCE) as the reference maintained at a constant distance $(3 \mathrm{~mm})$ from the specimen surface, a platinum counter electrode (CE) and the specimen as the working electrode (WE). Specimens were electrically insulated from the frame of the fatigue testing machine. The whole gauge section (area of interest) of the specimen was electrochemically monitored using a potentiostat device (Versastat4). During the CF tests, the free potential (OCP) value was monitored. Electrochemical impedance spectroscopy (EIS) analyses were carried out every $30 \mathrm{~min}\left(2.16 \times 10^{5}\right.$ cycles at $\left.120 \mathrm{~Hz}\right)$. Usual equivalent circuit modelling of the EIS data was used to extract physical properties of the electrochemical system by modelling the impedance data in terms of an equivalent electrical circuit. A solution resistance, $R_{\mathrm{s}}$, in series with a constant phase element, $C P E$, in parallel with a charge-transfer resistance, $R_{\mathrm{ct}}$, was considered, in particular to investigate the high frequency domain of electrochemical impedance measurements [39,41,42]. The high frequency range provides information on the passive film. The EIS investigation was performed in 
galvanostat mode. A small amplitude sine wave current modulation $\left( \pm 6 \mu \mathrm{A} / \mathrm{cm}^{2}\right)$ was carried out with a scanning frequency from $100 \mathrm{~Hz}$ up to $0.1 \mathrm{~Hz}$. All diagrams exhibit a capacitive response characterised by the first part of a half circle. A fitting program (Zsimwin) was used to provide the coefficient values of both the $C P E, R_{\mathrm{ct}}$ and $R_{\mathrm{s}}$. The capacitance of passive film was calculated using the $Q$ and $\alpha$ parameters of the $C P E$ using the Brug [43] formula given by:

$C=Q^{\frac{1}{\alpha}} \times R_{\mathrm{s}}^{\frac{1-\alpha}{\alpha}}$

The electrochemical investigation was carried out under both steady state and transient regimes. Two electrochemical techniques were used in this study: voltammetry and electrochemical impedance spectroscopy (EIS).

\section{Results and discussion}

\subsection{Corrosion fatigue crack initiation mechanism}

The effect of both the loading frequency and the aqueous corrosion on fatigue crack initiation life is detailed in [11]. Testing results show that the loading frequency $(10 \mathrm{~Hz}$ and $120 \mathrm{~Hz})$ has a little effect on the HCF strength in the aqueous solution as shown in Fig. 1. For a given stress amplitude the number of cycles to CFCI at $10 \mathrm{~Hz}$ are lower than those obtained at $120 \mathrm{~Hz}$. The S-N curves of the X12CrNiMoV12-3 stainless steel under fully reversed tension show a significant effect of aqueous corrosion on fatigue strength. The median fatigue strength at $10^{7}$ cycles in aqueous solution decreases of $33 \%$ compared to the one in air (Fig. 1).

The open circuit potential (OCP) of the X12CrNiMoV12-3 steel without any mechanical loading is approximately $+0.1 \mathrm{~V} / \mathrm{SCE}$ which corresponds to the passivation domain. However, the free potential measurements during CF tests show that, for all the corrosion fatigue tests leading to crack initiation, a decrease in the free potential to the activated corrosion peak potential is observed systematically (Fig. 2-a). This phenomenon is attributed to the damage of the protective (passive) film in aqueous solution due to the cyclic loading. For specimens which did not fail after $10^{7}$ cycles, under the stress amplitude equals to the median CF strength at this number of cycles, the free potential decrease was not observed (Fig. 2-b).

During corrosion fatigue tests Electrochemical Impedance Spectroscopy (EIS) were carried out to evaluate the passivation state of the tested specimen. For CF test leading to failure, two regimes were clearly observed: one without cyclic stress and one with cyclic stress. In the regime without cyclic stress, a low capacitance was measured. This result denotes the presence of a protective passive film. Once the cyclic stress is applied, the capacitance increases significantly. This result shows a progressive local rupture of the passive film induced by the applied cyclic loading (no generalised corrosion was observed after $\mathrm{CF}$ tests). Optical and SEM observations of the surface indicate that this OCP drop is associated to the development of corrosion pits at the surface. For not failed specimens, the capacitance increase was not observed, and the capacitance value was constant, less than $7 \mu \mathrm{F} / \mathrm{cm}^{2}$. This value corresponds to the capacitance of the passive layer of stainless steels measured without cyclic loading in the passive regime. This demonstrates that the aqueous media does not dissolve the passive film but that synergetic effects drive the process. AES Measurements were performed at ten different locations on the specimen surface in order to evaluate the thickness uniformity of the passive film. The half of the oxygen content in the passive film is considered [44,45] as the corresponding thickness of passive film (see Fig. 3) and was found to be uniform on the specimen surface. Its value is around $3 \mathrm{~nm}$ for the passive film formed in air.

We conclude that the passive film is broken by material strain due to the applied cyclic loading, causing increased local corrosive attack. The passive film rupture threshold corresponds to the median fatigue strength at $10^{7}$ cycles of the material in $\mathrm{A}_{\mathrm{s}}$ aqueous solution; it is noted $\Delta \sigma_{\text {th }}$. Exceeding this threshold stress range, the local deformations associated to the development of micro-plasticity induce strong incompatibilities between the bulk and the passive film that cannot be accommodated by the later. This results in local passive film failure that initiates the local corrosion process. The fractographic examination indicates that corrosion fatigue cracks essentially nucleated and grew from one corrosion defect [11]. A schematic illustration of this CFCI process is illustrated in Fig. 4. The proposed CFCI scenario contains tow essential periods leading to crack initiation from geometrical defect:

1. the local ruptures of the passive film by PSB emergence at the

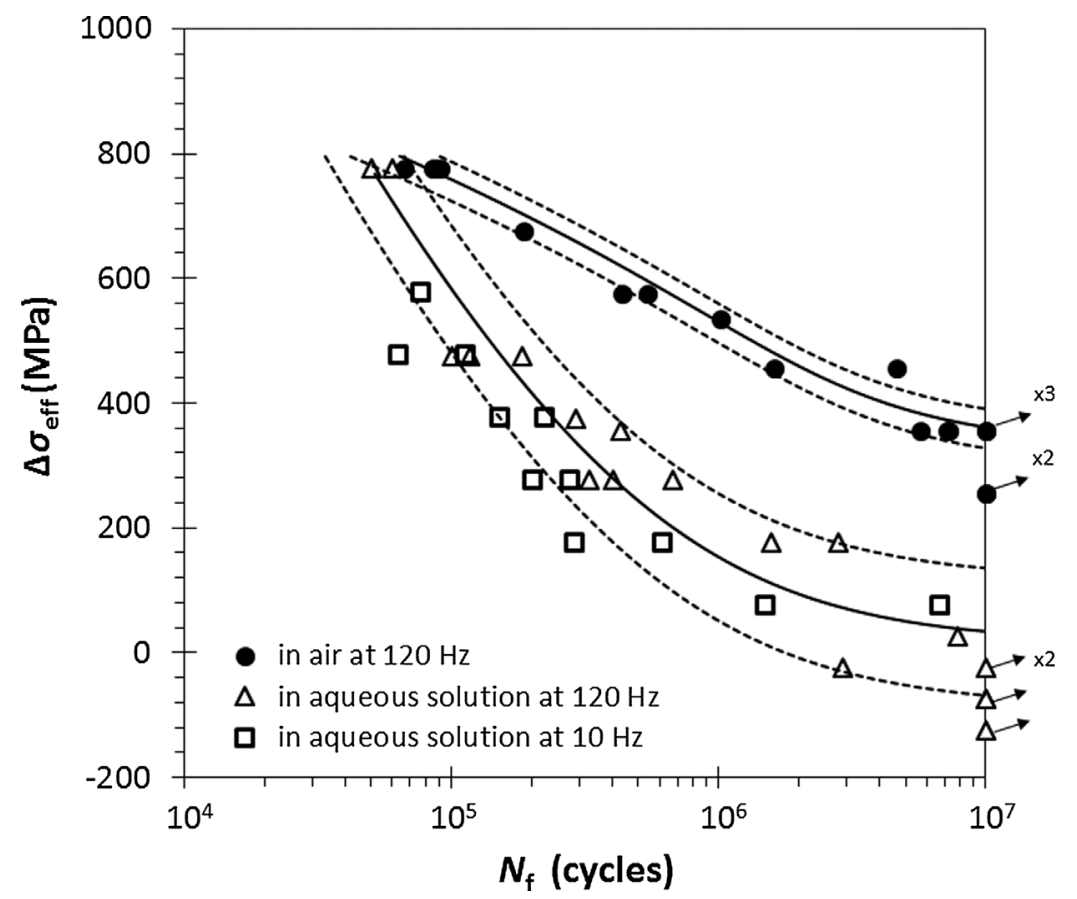

Fig. 1. Fatigue test results and S-N curves of corrosion fatigue tests under tension $R=-1$, for two different loading frequencies: $f=120 \mathrm{~Hz}$ and $f=10 \mathrm{~Hz}$. 

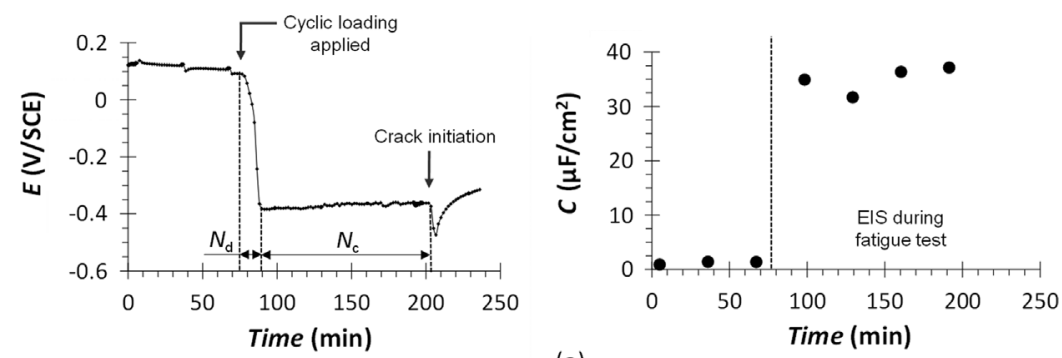

(a)
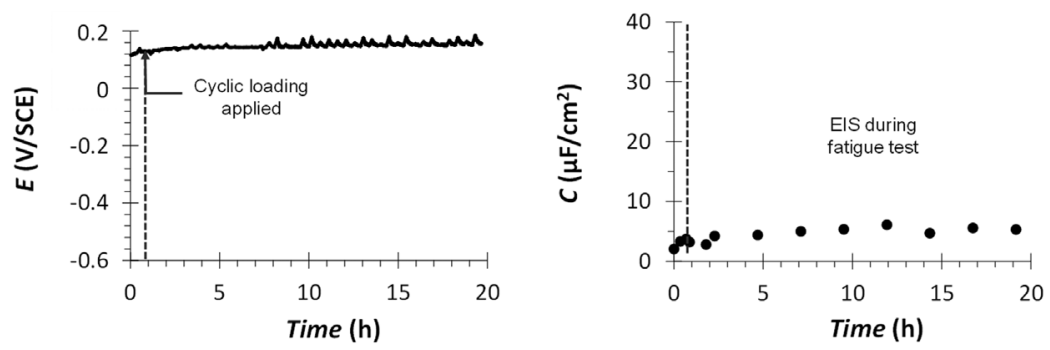

(b)

Fig. 2. Free potential (OCP) and capacitance of passive film (EIS) evolutions during corrosion fatigue test in $\mathrm{A}_{\mathrm{s}}$ aqueous solution under tension $R=-1$ : (a) CFCI at $9.4 \times 10^{5}$ cycles and (b) specimen without failure at $10^{7}$ cycles.

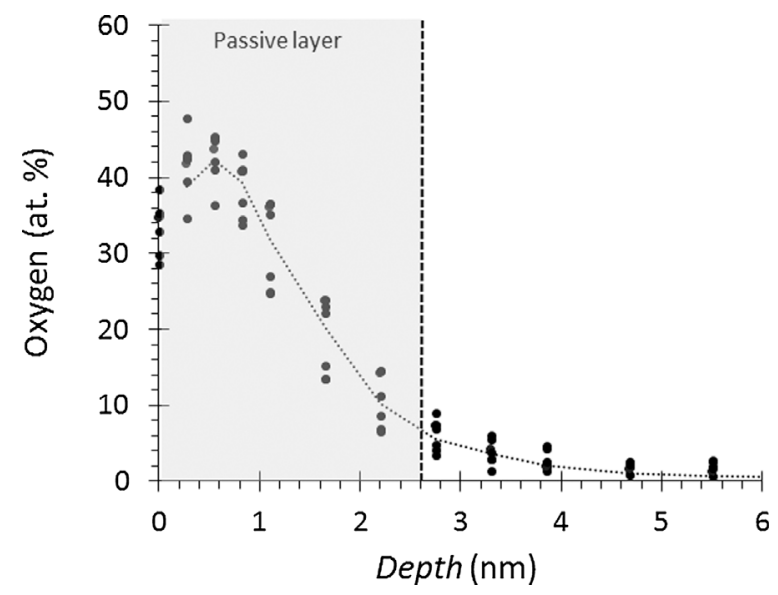

Fig. 3. Results of Auger measurements (AES) at the surface of the X12CrNiMoV12-3 martensitic stainless steel with passive film formed in air.

surface,

2. local dissolution in depassivated zones and initiation of localized geometrical defects,

These steps are identified on the free potential evolution curve (Fig. 2-a). The decrease of the free potential corresponds to local ruptures of the passive film and the plateau corresponds to the free metal dissolution around depassivation sites at the potential of the activated corrosion peak. In this case, the number of cycles to CFCI life $N_{\mathrm{f}}$ can be expressed by:

$N_{\mathrm{f}}=N_{\mathrm{d}}+N_{\mathrm{c}}$

where $N_{\mathrm{d}}$ is the number of cycles necessary to the local rupture of the passive film by PSBs emergence at the surface and $N_{\mathrm{c}}$ is the number of cycles needed to develop a critical corrosion defect for fatigue crack initiation.

\subsection{Analytical model}

\subsubsection{Depassivation life $\left(N_{d}\right)$}

The time necessary for the depassivation of the metal under cyclic
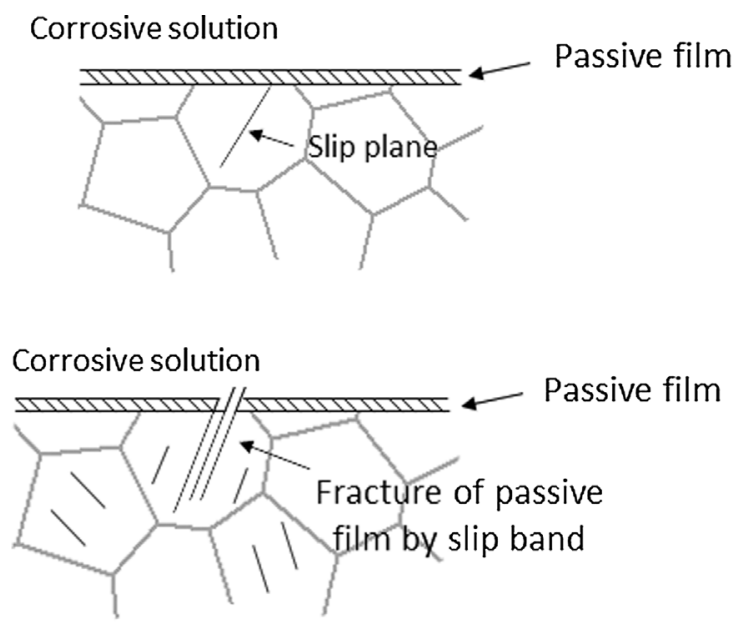

\section{Corrosive solution}

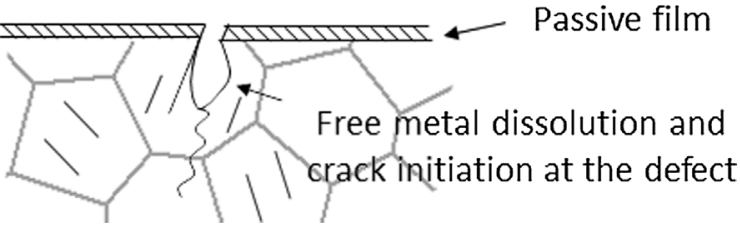

Fig. 4. Scenario of corrosion fatigue crack initiation on the $\mathrm{X} 12 \mathrm{CrNiMo12}-3$ martensitic stainless steel under a $120 \mathrm{~Hz}$ or $10 \mathrm{~Hz}$ loading frequency in the HCF regime $\left(10^{5}-10^{7}\right.$ cycles).

loading depends on both the kinematic of PSBs emergence, and the time needed to obtain PSB high enough to induce the passive film failure. Harvey [46] and Gerberich [47] described, from atomic force microscopy (AFM) measurements, the fraction of plasticity emerging at the free surface of a cyclically stressed specimen. Considering slip deformation, as depicted in Fig. 5, the amount of emerging strain at the surface during one cycle can be written as:

$f^{*} \Delta \epsilon^{\mathrm{p}}=\frac{\delta_{\mathrm{s}}}{h_{\mathrm{s}}}$

where $\delta_{s}^{\text {cum }}$ is the surface upset created by one cycle, $h_{\mathrm{s}}$ is the slip plane 


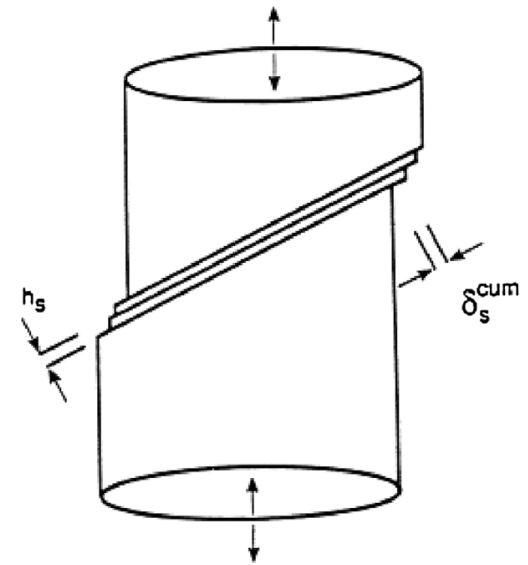

Fig. 5. Schematic of slip band height $\delta_{\mathrm{s}}^{\text {cum }}$, accumulated after $N$ cycles and average spacing between slip bands $h_{\mathrm{s}}$ on a single crystal from referecnce [47].

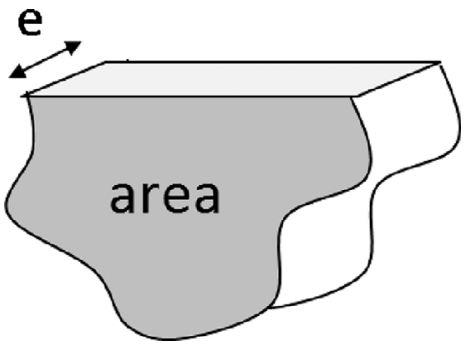

Fig. 6. Schematic model of the corrosion defect developed during corrosion fatigue test on martensitic stainless steel X12CrNiMoV12-3.

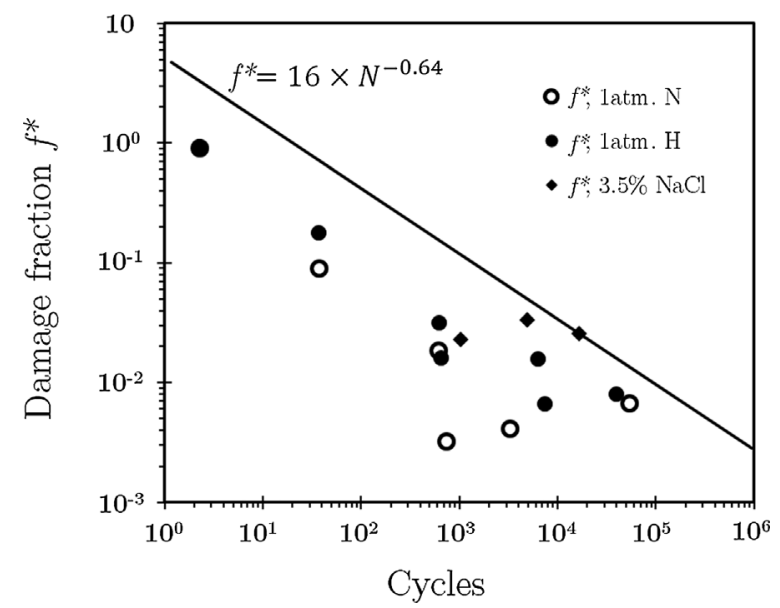

Fig. 7. Relation between the damage fraction $f^{*}$ and the number of cycle on HSLA steel, experimental data issue from reference [49].

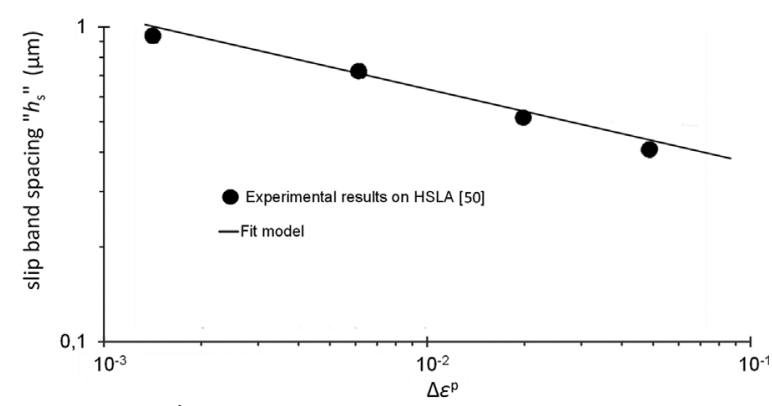

Fig. 8. Relation between PSB spacing, $h_{\mathrm{s}}$, and the plastic deformation range, $\Delta \varepsilon^{\mathrm{P}}$, on HSLA steel, experimental data issue from reference [50].

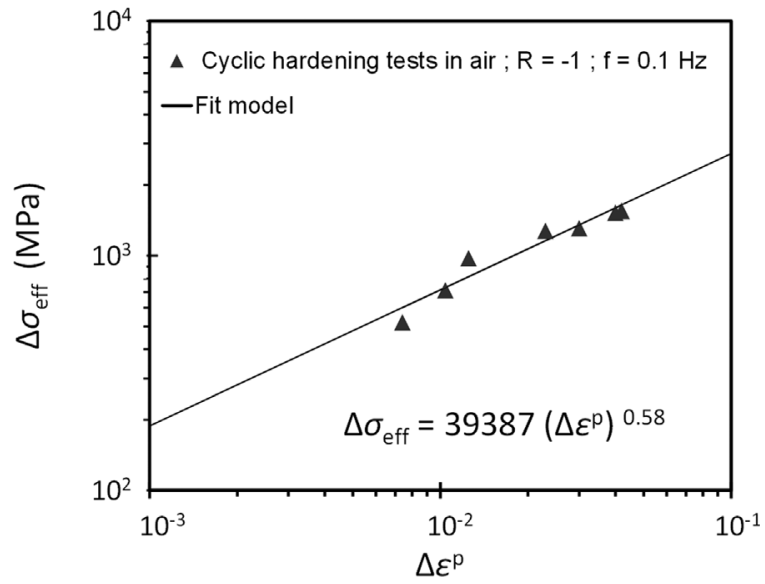

Fig. 9. Relation between the effective stress range, $\Delta \sigma_{\text {eff }}$, and the plastic deformation range, $\Delta \varepsilon^{\mathrm{P}}$, on the martensitic stainless steel X12CrNiMoV12-3.

Table 1

Calibrated parameter values in the depassivation life model Eq. (10).

$\begin{array}{ll}\text { From cyclic hardening tests } & k=39,389 \mathrm{MPa} \text { and } m=0.58 \\ \text { From Auger probe analysis } & \delta_{\mathrm{s}, \mathrm{th}}^{\text {cum }}=3 \mathrm{~nm} \\ \text { From AFM analysis } & \alpha=0.2, \beta=16 \text { and } \kappa=-0.64 \\ \text { Material parameters } & b=0.25 \mathrm{~nm} \text { and } G=80,000 \mathrm{MPa}\end{array}$

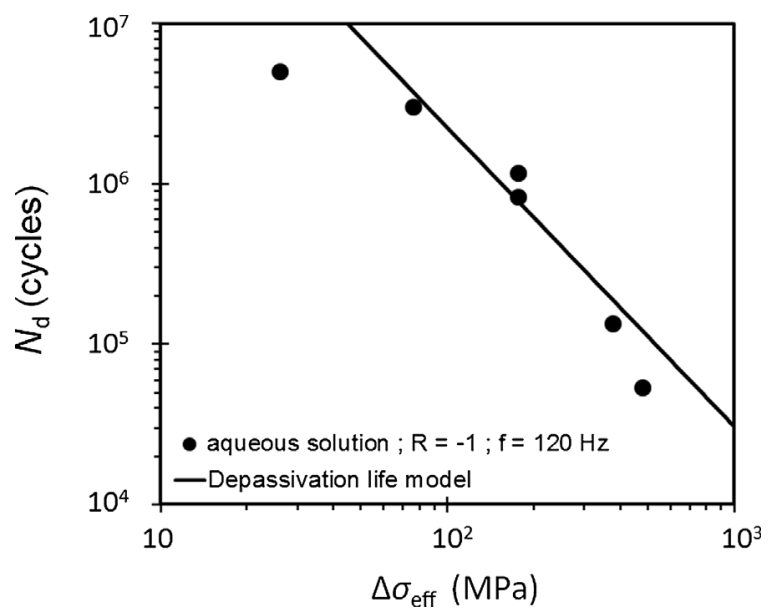

Fig. 10. Comparison between experimental data on the martensitic stainless steel $\mathrm{X} 12 \mathrm{CrNiMoV12}-3$ tested in the aqueous solution $\left(\mathrm{A}_{\mathrm{s}}\right)$ at $R=-1$ and the depassivation life model (Eq. (10)).

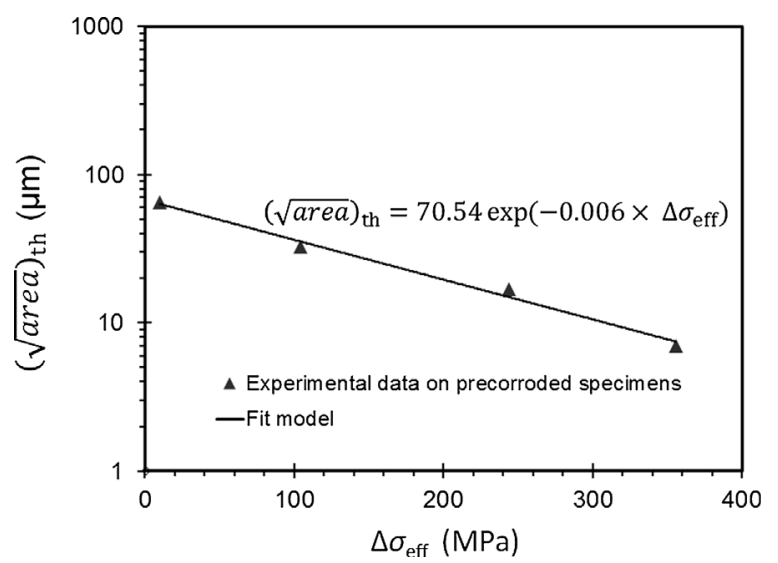

Fig. 11. Relation between the threshold defect size $(\sqrt{\text { area }})$ th for fatigue crack initiation and the effective stress range $\left(\Delta \sigma_{\text {eff }}\right)$. 
Table 2

Calibrated parameter values in the corrosion growth life model Eq. (14).

\begin{tabular}{ll}
\hline Material parameters & $\begin{array}{l}M=55.85 \mathrm{~g} / \mathrm{mol}, z=2 \text { and } \rho=7.8 \mathrm{~g} / \\
\mathrm{cm}^{3}\end{array}$ \\
From optical microscope & $e=2 \mu \mathrm{m}$ \\
From in-situ electrochemical & $I_{\text {corr }}=4.5 \mu \mathrm{A}$; the exposed surface is \\
measurement & $1 \mathrm{~cm}^{2}$ \\
From fatigue tests on precorroded & $C=70.45 \mu \mathrm{m}$ and $n=-0.006 \mathrm{MPa}^{-1}$ \\
specimens &
\end{tabular}

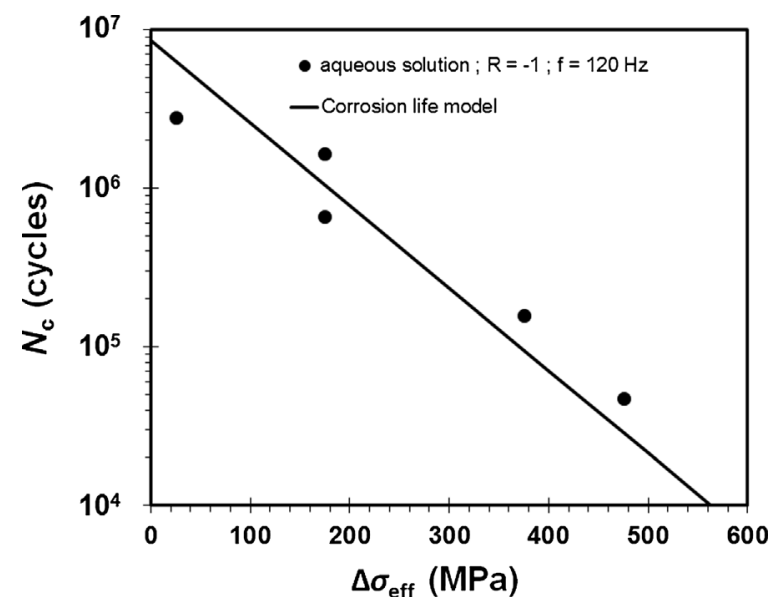

Fig. 12. Comparison between the number of cycles to develop a critical defect (experimental data) on the martensitic stainless steel X12CrNiMoV12-3 tested in the aqueous solution $\left(\mathrm{A}_{s}\right)$ at $R=-1$ and the corrosion growth life model (Eq. (14)).

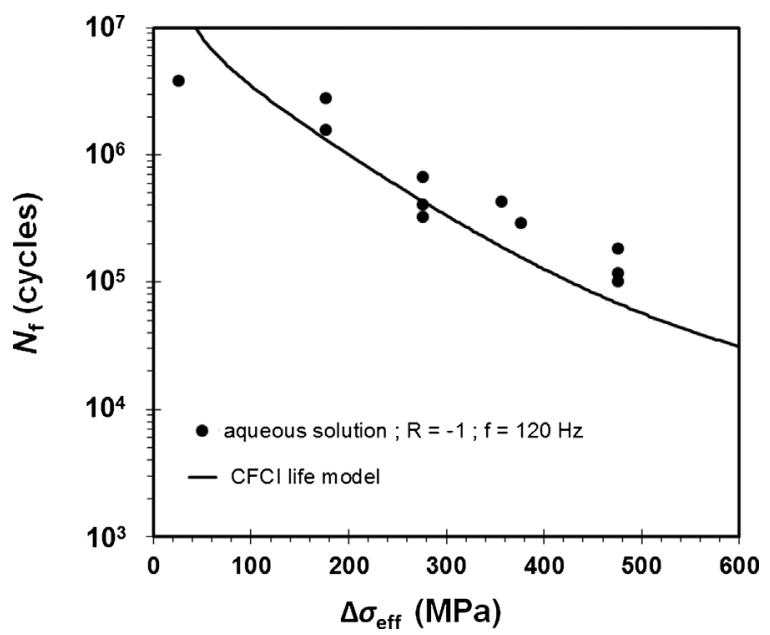

Fig. 13. Comparison between the number of cycles to fatigue crack initiation (experimental data) on the martensitic stainless steel X12CrNiMoV12-3 tested in the aqueous solution $\left(\mathrm{A}_{s}\right.$ ) at the loading frequency $f=120 \mathrm{~Hz}$ and the CFCI life model (Eq. (15)).

spacing. The $\delta_{\mathrm{s}} / h_{\mathrm{s}}$ parameter represents a strain and the quantity $f^{*} \Delta \epsilon^{\mathrm{p}}$ reflects the fact that only a fraction of the dislocations created during a given stress cycle can emerge at the surface; i.e. $f^{*}$ is the fraction of emerging plasticity at the free surface. For $N$ cycles, the cumulated strain (displacement over gauge length) can be written as:

$\frac{\delta_{\mathrm{s}}^{\mathrm{cum}}}{h_{\mathrm{s}}}=f^{*} \Delta \epsilon^{\mathrm{p}} N$

where $\delta_{\mathrm{s}}^{\text {cum }}$ is the cumulative surface upset. Gerberich et al. [47] determined the experimental evolution of the damage fraction, $f^{*}$, versus the number of cycles, $N$, for the specimens under fully reversed fatigue loading in air and in $0.9 \%$ saline water under plastic strain ranges between $5 \times 10^{-4}$ and $2 \times 10^{-3}$. These authors show that the fraction of emerging plasticity vs. the number of cycles can be expressed as:

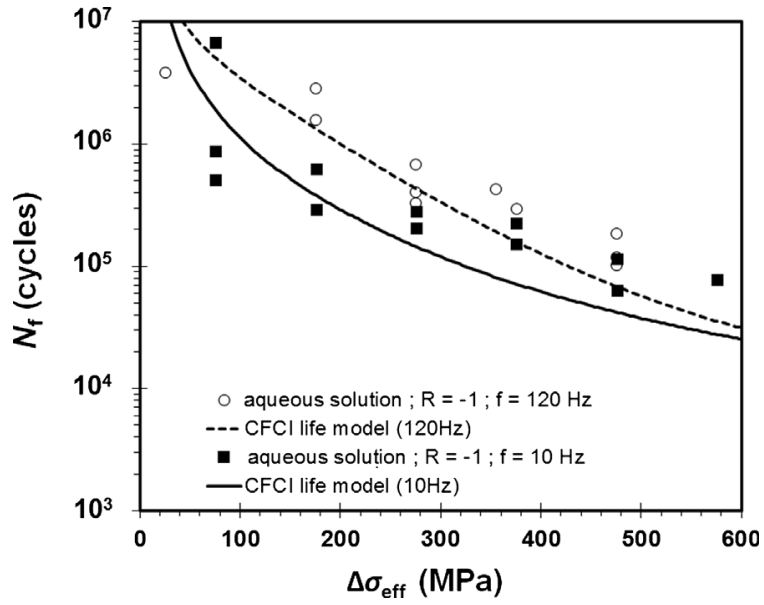

Fig. 14. Comparison between experimental data on the martensitic stainless steel X12CrNiMoV12-3 tested in the aqueous solution $\left(\mathrm{A}_{s}\right)$ with two loading frequency $f=120 \mathrm{~Hz}$ and $f=10 \mathrm{~Hz}$ at stress ratio $R=-1$ and the CFCI life model (Eq. (15)).

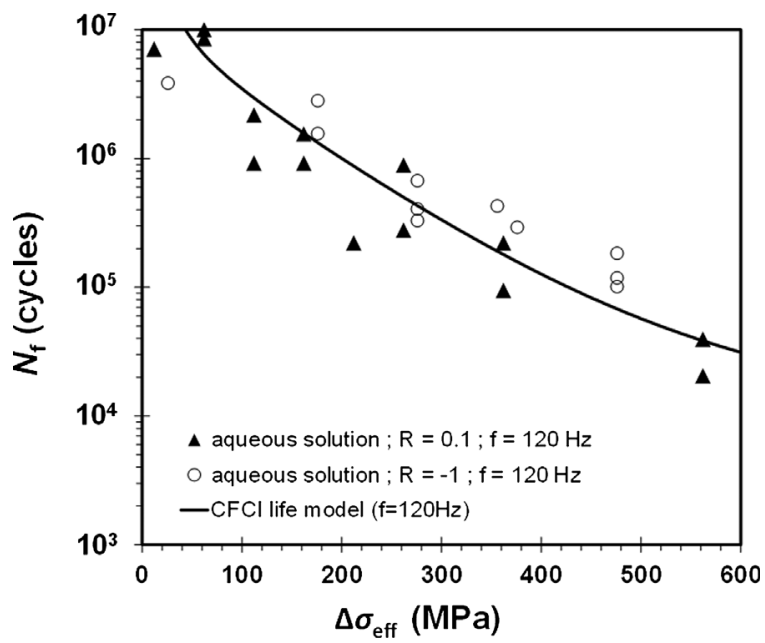

Fig. 15. Comparison between experimental data on the martensitic stainless steel $\mathrm{X} 12 \mathrm{CrNiMoV12}-3$ tested in the aqueous solution $\left(\mathrm{A}_{s}\right)$ with two stress ratio $R=-1$ and $R=0.1$ at $f=120 \mathrm{~Hz}$ and the CFCI life model (Eq. (15)).

$f^{*}=\beta \times N^{\kappa}$

where $\beta$ and $\kappa$ are two constants depending on the grain size of the material and the environment of the fatigue tests. Harvey et al. [46] show that the slip band spacing can continue to decrease under cyclic loading as long as the applied stress increases. The slip band spacing $h_{s}$ is inversely proportional to the effective cyclic stress range and it is expressed by:

$h_{\mathrm{s}}=\frac{\alpha \mathrm{G} \mathrm{b}}{\Delta \sigma_{\text {eff }}}$

where $G$ is the shear modulus, $b$ the Burgers vector, $\Delta \sigma_{\text {eff }}$ is the cyclic effective stress range and $\alpha$ is a fitting constant depending on the material grain size [46]. The definition of $\alpha$ needs AFM observations coupled with fatigue test at different stress levels to determine the empirical relation between $h_{\mathrm{s}}$ and the applied cyclic stress. $\Delta \sigma_{\mathrm{th}}$ is the median corrosion fatigue strength at $10^{7}$ cycles determined experimentally by the stair case method. This corresponds to the threshold stress range of the passive film cracking under cyclic loading. Also, the cumulative surface upset $\delta_{\mathrm{s}}^{\text {cum }}$ can be obtained by substituting Eq. (6) into Eq. (4).

$\delta_{\mathrm{s}}^{\mathrm{cum}}=\beta \alpha \mathrm{Gb} \frac{\Delta \varepsilon^{\mathrm{p}}}{\Delta \sigma_{\mathrm{eff}}} N^{(\kappa+1)}$ 
The number of cycles $N_{\mathrm{d}}$ necessary to provoke the failure of the passive film corresponds to the threshold value, $\delta_{\mathrm{s}, \mathrm{th}}^{\text {cum }}$, of $\delta_{\mathrm{s}}^{\text {cum }}$ to break the passive layer (Eq. (8)).

$N_{d}=\left(\frac{\delta_{\mathrm{s}, \mathrm{th}}^{\mathrm{cum}}}{\beta \alpha \mathrm{Gb}}\right)^{1 /(\kappa+1)}\left(\frac{\Delta \sigma_{\mathrm{eff}}}{\Delta \varepsilon^{\mathrm{p}}}\right)^{1 /(\kappa+1)}$

The relation between $\Delta \sigma_{\text {eff }}$ and $\Delta \varepsilon^{p}$ is experimentally determined for the $\mathrm{X} 12 \mathrm{CrNiMoV12}-3$ using tension-compression tests under various imposed plastic strain range as follows:

$\Delta \sigma_{\text {eff }}=k\left(\Delta \varepsilon^{\mathrm{p}}\right)^{m}$

where $k$ et $m$ are material parameters identified by fitting experimental cyclic hardening data.

Considering the depassivation stage for the formation of the fatigue crack, the number of cycles, $N_{\mathrm{d}}$, necessary to break the passive film can be obtained by substituting Eq. (9) into Eq. (8) so that:

$N_{\mathrm{d}}=\left(\frac{\delta_{\mathrm{s}, \text { th }}^{\mathrm{cum}} \times k^{1 / m}}{\beta \alpha \mathrm{G} \mathrm{b}}\right)^{1 /(\kappa+1)}\left(\Delta \sigma_{\text {eff }}\right)^{\frac{m-1}{(\kappa+1) m}}$

Note that $G$ and $b$ are material parameters. Furthermore, $\alpha, \beta$ and $\kappa$ can be determined by AFM measurements.

\subsubsection{Number of cycle for corrosion defect growth $\left(N_{c}\right)$}

The development of corrosion defects constitutes the second period of the corrosion fatigue crack initiation mechanism on the X12CrNiMoV12-3. This step represents the anodic dissolution of the depassivated surface zones due to the local PSB emergence. The corrosion rate can be expressed by the Faraday equation $[4-6,48]$ :

$\frac{\mathrm{d} V_{\mathrm{C}}}{\mathrm{d} t}=\frac{M I_{\text {corr }}}{z \mathrm{~F} \rho}$

where $I_{\text {corr }}$ is the mean value of the electrochemical current achieved during the corrosion growth period.

The volume of the dissolved metal during corrosion growth period is given by

$V_{\mathrm{C}}=\frac{M I_{\text {corr }}}{z \mathrm{~F} \rho} t$

The fractographic analysis of corrosion fatigue test specimens reveals the presence of a single crack initiation zone localised around a corrosion defect. We consider that the total volume corresponds to a single corrosion defect at the origin of the corrosion fatigue crack initiation. The shape of the corrosion defect can be estimated by the defect area (area) and the average thickness of slip bands (e) (Fig. 6).

The volume of the corrosion defect, $V_{\mathrm{C}}$, is expressed by Eq. (13) using the geometrical parameter of Murakami $(\sqrt{\text { area }})$ [38].

$V_{\mathrm{C}}=(\sqrt{\mathrm{area}})^{2} e$

The fatigue crack initiation life at a number of cycles less than $10^{7}$ cycles occurs when the size of the corrosion defect reaches a critical value for the initiation of a fatigue crack. This critical size of corrosion defect $(\sqrt{\text { area }})_{\text {th }}$ depends on the level of the effective stress range.

The number of cycles necessary to achieve the critical corrosion defect size can be obtained by:

$N_{\mathrm{c}}=t_{\mathrm{c}} f=\frac{z \mathrm{~F} \rho e}{M I_{\text {corr }}}\left((\sqrt{\text { area }})_{\mathrm{th}}\right)^{2} f$

where $f$ is the loading frequency of the fatigue test.

\subsubsection{Expression of number of cycles to CFCI $\left(N_{f}\right)$}

The fatigue life prediction model, based on the local depassivation by slip bands emergence and corrosion defect growth in depassivated area, yields to the relation between the number of cycles to crack initiation, in the HCF regime (between $10^{5}$ and $10^{7}$ cycles), $N_{\mathrm{f}}$, and material and mechanical parameters (Eq. (15)).
$N_{\mathrm{f}}=\left(\frac{\delta_{\mathrm{s}, \mathrm{d}}^{\mathrm{cum}} k^{1 / m}}{\beta \alpha \mathrm{G} \mathrm{b}}\right)^{1 /(\kappa+1)}\left(\Delta \sigma_{\mathrm{eff}}\right)^{\frac{m-1}{(\kappa+1) m}}+\frac{z \mathrm{~F} \rho e}{M I_{\text {corr }}}\left((\sqrt{\text { area }})_{\mathrm{th}}\right)^{2} f$

\subsection{Experimental identification of the CFCI model parameters}

Tow sets of material parameters must be determined: one set in the depassivation life model and one set in the local corrosion life model. The CFCI model parameters were identified from experimental data on the martensitic stainless steel X13CrMoV12-3.

\subsubsection{Parameters identification needed to compute the depassivation life} $\left(N_{d}\right)$

The actual determination of the constants: $\beta, \alpha$ and $\kappa$ involves AFM measurements on the tested material. In this study, these parameters were estimated using literature data. Marsh et al. [49] showed that the mechanism which produces slip band emergence is identical for the two environments (air and saline water with 0.9 mass $\% \mathrm{NaCl}$ ). However, this phenomenon strongly depends on the average grain size of the material [46]. Based on this argument, the material parameters $\beta, \alpha$ and $\kappa$ (in Eqs. (5) and (6)) were estimated using experimental data obtained in the literature (see Figs. 7 and 8) $[49,50]$ on fatigue crack nucleation in fine grain HSLA steel tested in 0.9 mass $\% \mathrm{NaCl}$ aqueous solution (vs. 0.6 mass $\% ~ \mathrm{NaCl}$ in our study). The typical martensite lath dimension is around $2-3 \mu \mathrm{m}$ in HSLA steel $[49,50]$, consequently these data can be used to estimate these parameters on the material of the present study. The fitted curve and the experimental data are shown in Fig. 8.

Cyclic hardening tests were carried out at imposed cyclic strain on the martensitic stainless steel X12CrNiMoV12-3 to calibrate $k$ and $m$ parameters (Eq. (9)). The plastic deformation, $\Delta \varepsilon^{\mathrm{p}}$, and the stress range, $\Delta \sigma_{\text {eff }}$, were calculated using the stabilized cycle (at $N_{\mathrm{f}} / 2$ ). The fitted curve and experimental data for unixial cyclic hardening are shown in Fig. 9.

The threshold value, $\delta_{\mathrm{s}, \mathrm{th}}^{\mathrm{cum}}$, of $\delta_{\mathrm{s}}$ to break the passive layer (Eq. (8)) corresponds to the passive layer thickness determined experimentally from AES measurements given in Fig. 2. The values of material parameters $b$ and $G$ were calibrated using experimentally data obtained from the literature.

The calibrated values of the depassivation model and identification experimental techniques are given in Table 1.

Fig. 10 presents the evolution of the depassivation life, $N_{\mathrm{d}}$, in $\mathrm{A}_{\mathrm{s}}$ as a function of the effective stress range, $\Delta \sigma_{\text {eff }}$. Experimental data of $N_{\mathrm{d}}$ was obtained using the OCP measurement during corrosion fatigue tests on the martensitic stainless steel X12CrNiMoV12-3 (Fig. 2-a). The predicted depassivation life, $N_{\mathrm{d}}$, agrees with the experimental data.

\subsubsection{Parameters identification needed to compute the corrosion growth life} $\left(N_{c}\right)$

In the case of the stainless steel, we consider the oxidation degree of $\mathrm{Fe}^{2+}$, to calculate the molar mass $(M=55.85 \mathrm{~g} / \mathrm{mol}$ and $z=2) . \mathrm{F}$ is the Faraday constant and $\rho$ is the density of the studied material equal to 7 , $8 \mathrm{~g} / \mathrm{cm}^{3}$. The corrosion current, $I_{\text {corr }}$, is considered as a constant value independent on the effective stress range levels of the fatigue tests. The corrosion current density value is around $i_{\text {corr }}=4.5 \mu \mathrm{A} / \mathrm{cm}^{2}$ at the free potential equal to $-0.044 \mathrm{~V} / \mathrm{SCE}$. It was determined experimentally determined by in-situ electrochemical measurements during corrosion fatigue test. The relation between the threshold defect size $(\sqrt{\text { area }})_{\text {th }}$ and the effective stress range, $\Delta \sigma_{\text {eff }}$, is given by:

$(\sqrt{\text { area }})_{\text {th }}=C \exp \left(n \Delta \sigma_{\text {eff }}\right)$

where $C$ and $n$ are two material parameters identified by fitting of fatigue data obtained on precorroded specimens (Fig. 11). A study of the effect of the corrosion defect size on the fatigue crack initiation, when no mechanical/corrosion coupling occurs, can be found in [36].

The calibrated values of corrosion growth model and identification experimental techniques are given in Table 2. 
Fig. 12 shows the evolution of the corrosion growth life, $N_{\mathrm{c}}$, in saline water $\left(\mathrm{A}_{s}\right)$ as a function of the effective stress range $\Delta \sigma_{\text {eff. }}$ The predicted life, $N_{\mathrm{c}}$, agrees well with the experimental data obtained using the OCP measurement during corrosion fatigue tests on the martensitic stainless steel X12CrNiMoV12-3 (Fig. 2-a).

\subsection{CFCI life model verification}

The results of the proposed CFCI model are compared with corrosion fatigue data on martensitic stainless steel X12CrNiMoV12-3 tested in $\mathrm{A}_{\mathrm{s}}$ aqueous solution at loading frequency $f=120 \mathrm{~Hz}$ and stress ratio $R=-1$ (Fig. 13). As it can be seen, the calculated corrosion model (Eq. (15)) gives a good assessment of the experimental results on $\mathrm{X} 12 \mathrm{CrNiMoV12}$-3. It is worth noting that the predicted CFCI life, $N_{\mathrm{f}}$, fits well the experimental ones while none parameter of the model directly uses these specific data.

\subsubsection{Effect of the loading frequency on the CFCI life}

The effect of the loading frequency in corrosion fatigue is related to the repassivation rate after local ruptures of the passive film and possibly modifies the corrosion growth period. However, it has been shown in a previous study [11] that the repassivation rate of the martensitic stainless steel $\mathrm{X} 12 \mathrm{CrNiMoV12}-3$ in $\mathrm{A}_{s}$ aqueous solution is significantly lower than the characteristic time of the slip band emergence induced by the applied cyclic stress at a loading frequency of 10 and $120 \mathrm{~Hz}$. This finding is in agreement with the CFCI life model (Eq. (14)). The loading frequency effect on the experimental CFCI life is given in Fig. 14. It shows that the loading frequency (at $10 \mathrm{~Hz}$ and $120 \mathrm{~Hz}$ ) has an effect on the CFCI life in aqueous solution $\left(A_{s}\right)$ : this effect is well captured by the proposed approach. This effect may become more important for very low frequencies and should be checked with corrosion fatigue tests at lower loading frequencies where the repassivation characteristic time is larger than the slip band emergence one.

\subsubsection{Effect of the CFCI threshold}

For the studied X12CrNiMoV12-3 martensitic stainless steel, the CFCI threshold corresponds to the stress range of non developing slip bands to fracture the passive film in HCF regime $\left(10^{5}\right.$ to $10^{7}$ cycles). The CFCI threshold depends on the alloy microstructure, the interaction between the alloy and environment, and on the fatigue loading conditions (stress range, stress ratio, etc.). The effect of stress ratio on CFCI threshold was investigated in this study. Tow stress ratio were considered $R=-1$ and $R=0.1$. CF results show that the stress ratio affects the threshold stress, $\Delta \sigma_{\text {th }}$, of CFCI. Considering the effective stress range, $\Delta \sigma_{\text {eff, }}$, the CFCI life, $N_{\mathrm{f}}$, at stress ratio $R=-1$ and $R=0.1$ (given in Fig. 15), tend to be similar. Fig. 15 shows that the predicted CFCI life model gives good estimation of the experimental data at $R=-1$ and $R=0.1$ using the threshold stress range experimentally identified for each stress ratio.

\section{Conclusions}

An analytical model able to compute the CFCI life, in HCF regime, has been proposed. This is containing a pit initiation model and corrosion growth one. It has been compared with experimental data on the martensitic stainless steel X12CrNiMoV12-3 and gives good results. The following key conclusions were obtained:

1. In-situ electrochemical measurements during corrosion fatigue tests show that the CFCI is due to (i) the local depassivation of the passive film and (ii) the corrosion pitting.

2. The depassivation period is associated to the slip bands emergence at the surface of the specimen. A depassivation life model, based on Gerberich and Harvey $[46,47]$ was identified to predict the number of cycles needed to fracture the passive film. The calculated results agreed well with the experimental data.
3. The transition between corrosion defect and crack propagation is defined by the size of the critical defects, which was chosen considering fatigue tests on precorroded specimens. Using the Faraday law, the corrosion rate under cyclic loading was estimated to compute the corrosion growth period of the critical corrosion defect. The calculated results agree well with the experimental data.

4. The proposed CFCI life model in HCF regime (Eq. (15)) takes into account the coupling effect between the pit initiation (depassivation) and the effective stress range. The consistency between the experimental and analytical results suggests that the effective stress range has an important effect on the corrosion process during the fatigue tests. In the same corrosion media, the calculated CFCI lives for stress ratio $R=0.1$ and $R=-1$ agree well with the experimental data.

5. The effect of the loading frequency mostly concerns corrosion growth, while the depassivation phenomenon is not affected in the frequency range investigated here. Tow loading frequencies $120 \mathrm{~Hz}$ and $10 \mathrm{~Hz}$ were studied. With the decrease of loading frequency the corrosion time increases for the same number of cycles and the fatigue life is extended. The proposed CFCI life model gives a good estimation of the experimental data at $120 \mathrm{~Hz}$ and $10 \mathrm{~Hz}$.

\section{Acknowledgements}

This work was carried out in the framework of the ARCAM project, with the financial support of DGCIS, Aquitaine, Auvergne and MidiPyrenees French regions. The authors thankfully acknowledge the industrial partners for the project, including Ratier-Figeac, Aubert et Duval, Olympus, and the academic partners at the Material Department of ICAM and the CIRIMAT (Toulouse University, France).

\section{References}

[1] Y. Kondo, Prediction of fatigue crack initiation life based on pit growth, Corrosion 45 (1979) 7-11.

[2] G. Chen, K.-C. Wan, M. Gao, R. Wei, T. Flournoy, Transition from pitting to fatigue crack growth - modeling of corrosion fatigue crack nucleation in a 2024-T3 aluminium alloy, Mater. Sci. Eng. A 19 (1996) 126-132.

[3] S. Xu, Crack initiation mechanisms for low cycle fatigue of type 316Ti stainless steel in high temperature water, Mater. Sci. Eng. A (2008) 16-25.

[4] C. Laird, D.J. Duquette, Mechanisms of fatigue crack nucleation, corrosion fatigue: chemistry, mechanics and microstructure, Nace-2 (1973) 88.

[5] M. Muller, Theoretical consideration on corrosion fatigue crack in initiation, Metall. Trans. A 13A (1982) 649.

[6] T. Magnin, L. Coudreuse, Corrosion fatigue mechanisms in BBC stainless steels, Acta Metall. 35 (1987) 2105-2113.

[7] R.E. Stoltz, R.M. Pelloux, Mechanisms of corrosion fatigue crack propagation in AlZn-Mg alloys, Metall. Trans. 3 (9) (1972) 2433-2441.

[8] P. Hu, Q. Meng, W. Hu, F. Shen, Z. Zhan, L. Sun, A continuum damage mechanics approach coupled with an improved pit evolution model for the corrosion fatigue of aluminum alloy, Corros. Sci. 113 (2016) 78-90.

[9] S. Zhou, M. Lukaszewicz, A. Turnbull, Small and short crack growth and the solution-conductivity dependent electrochemical crack size effect, Corros. Sci. 97 (2015) 25-37.

[10] B.M. Schnbauer, S.E. Stanzl-Tschegg, A. Perlega, R.N. Salzman, N.F. Rieger, A. Turnbull, S. Zhou, M. Lukaszewicz, D. Gandy, The influence of corrosion pits on the fatigue life of 17-4PH steam turbine blade steel, Eng. Fracture Mech. 147 (2015) $158-175$.

[11] M. El-May, T. Palin-Luc, N. Saintier, O. Devos, Effect of corrosion on the high cycle fatigue strength of martensitic stainless steel X12CrNiMoV12-3, Int. J. Fatigue 47 (2013) 330-339.

[12] Y. Huang, S.-T. Tu, F.-Z. Xuan, Pit to crack transition behavior in proportional and non-proportional multiaxial corrosion fatigue of 304 stainless steel, Eng. Fracture Mech. 184 (2017) 259-272.

[13] N.E.C. Co, J.T. Burns, Effects of macro-scale corrosion damage feature on fatigue crack initiation and fatigue behavior, Int. J. Fatigue 103 (2017) 234-247.

[14] M. Amiri, A. Arcari, L. Airoldi, M. Naderi, N. Iyyer, A continuum damage mechanics model for pit-to-crack transition in AA2024-T3, Corros. Sci. 98 (2015) 678-687.

[15] J. Tan, X. Wu, E.-H. Han, W. Ke, X. Wang, H. Sun, Strain-rate dependent fatigue behavior of 316L stainless steel in high-temperature water, J. Nucl. Mater. 489 (2017) 33-41.

[16] K. Asami, K. Hashimoto, S. Shimodaira, An XPS study of the passivity of a series of iron-chromium alloys in sulphuric acid, Corros. Sci. 18 (2) (1978) 151-160.

[17] S. Marcelin, N. Pébère, S. Régnier, Electrochemical characterisation of a martensitic stainless steel in a neutral chloride solution, Electrochim. Acta 87 (2013) 32-40. 
[18] R.-H. Jung, H. Tsuchiya, S. Fujimoto, XPS characterization of passive films formed on type 304 stainless steel in humid atmosphere, Corros. Sci. 58 (2012) 62-68.

[19] Z. Cui, Z. Liu, L. Wang, X. Li, C. Du, X. Wang, Effect of plastic deformation on the electrochemical and stress corrosion cracking behavior of X70 steel in near-neutral ph environment, Mater. Sci. Eng.: A 677 (2016) 259-273.

[20] A.A. Ahmed, M. Mhaede, M. Wollmann, L. Wagner, Effect of surface and bulk plastic deformations on the corrosion resistance and corrosion fatigue performance of AISI 316L, Surf. Coat. Technol. 259 (Part C) (2014) 448-455.

[21] H. Wu, B. Yang, Y. Shi, O. Gao, Y. Wang, Crack initiation mechanism of Z3CN20.09M duplex stainless steel during corrosion fatigue in water and air at $290^{\circ}$ C, J. Mater. Sci. Technol. 31 (11) (2015) 1144-1150.

[22] T.S. Sudarshan, T.S. Srivatsan, D.P. Harvey, Fatigue processes in metals-role of aqueous environments, Eng. Fracture Mech. 36 (6) (1990) 827-852.

[23] T. Zhao, Z. Liu, C. Du, C. Dai, X. Li, B. Zhang, Corrosion fatigue crack initiation and initial propagation mechanism of E690 steel in simulated seawater, Mater. Sci. Eng.: A 708 (2017) 181-192.

[24] W. Zhao, Y. Wang, T. Zhang, Y. Wang, Study on the mechanism of high-cycle corrosion fatigue crack initiation in x80 steel, Corros. Sci. 57 (2012) 99-103.

[25] R. Oltra, V. Vignal, Recent advances in local probe techniques in corrosion research - analysis of the role of stress on pitting sensitivity, Corros. Sci. 49 (1) (2007) $158-165$.

[26] O. Devos, C. Gabrielli, B. Tribollet, Simultaneous EIS and in situ microscope observation on a partially blocked electrode application to scale electrodeposition, Electrochim. Acta 51 (8-9) (2006) 1413-1422.

[27] P.T. Brewick, N. Kota, A.C. Lewis, V.G. DeGiorgi, A.B. Geltmacher, S.M. Qidwai, Microstructure-sensitive modeling of pitting corrosion: effect of the crystallographic orientation, Corros. Sci. 129 (2017) 54-69.

[28] R.W. Staehle, Transient stability of passive films in aqueous solutions, Corros. Sci. 49 (1) (2007) 7-19.

[29] A. Turnbull, L. Wright, Modelling the electrochemical crack size effect on stress corrosion crack growth rate, Corros. Sci. 126 (2017) 69-77.

[30] G. Murtaza, R. Akid, Empirical corrosion fatigue life prediction models of a high strength steel, Eng. Fracture Mech. 67 (5) (2000) 461-474.

[31] S. Ishihara, S. Saka, Z. Nan, T. Goshima, S. Sunada, Prediction of corrosion fatigue lives of aluminium alloy on the basis of corrosion pit growth law, Fatigue Fracture Eng. Mater. Struct. 29 (6) (2006) 472-480.

[32] R. Ebara, Corrosion fatigue crack initiation in 12\% chromium stainless steel, Mater. Sci. Eng. A 13 (2007) 468-470.

[33] M. Klein, G. Frieling, F. Walther, Corrosion fatigue assessment of creep-resistant magnesium alloys DieMag422 and AE42, Eng. Fracture Mech. (2017).

[34] J.M. Finney, C. Laird, Strain localization in cyclic deformation of copper single crystals, Philos. Mag. 31 (2) (1975) 339-366.

[35] I. Aubert, N. Saintier, J.-M. Olive, F. Plessier, A methodology to obtain data at the slip-band scale from atomic force microscopy observations and crystal plasticity simulations. Application to hydrogen-induced slip localization on AISI316L stainless steel, Acta Mater. 104 (2016) 9-17.

[36] M. El-May, N. Saintier, T. Palin-Luc, O. Devos, Non-local high cycle fatigue strength criterion for metallic materials with corrosion defects, Fatigue Fracture Eng. Mater. Struct. 38 (9) (2015) 1017-1025.

[37] T. Palin-Luc, R. Perez-Mora, C. Bathias, G. Domenguez, P.C. Paris, J.L. Arana, Fatigue crack initiation and growth on a steel in the very high cycle regime with sea water corrosion, Eng. Fracture Mech. (2010) 1953-1962.

[38] Y. Murakami, Metal Fatigue: Effects of Small Defects and Nonmetallic Inclusions, Ed. Elsevier, Oxford, Boston, 2002.

[39] S. Marcelin, N. Pébère, S. Régnier, Electrochemical investigations on crevice corrosion of a martensitic stainless steel in a thin-layer cell, J. Electroanal. Chem. 737 (2015) 198-205.

[40] J. Trompette, L. Arurault, S. Fontorbes, L. Massot, Influence of the anion specificity on the electrochemical corrosion of anodized aluminum substrates, Electrochim. Acta 55 (8) (2010) 2901-2910.

[41] M. Monnot, V. Roche, R. Estevez, M. Mantel, R.P. Nogueira, Molybdenum effect on the sulfide stress corrosion of a super martensitic stainless steel in sour environment highlighted by electrochemical impedance spectroscopy, Electrochim. Acta 252 (2017) 58-66.

[42] S.-Y. Lu, K.-F. Yao, Y.-B. Chen, M.-H. Wang, X. Liu, X. Ge, The effect of tempering temperature on the microstructure and electrochemical properties of a $13 \mathrm{wt} . \% \mathrm{Cr}$ type martensitic stainless steel, Electrochim. Acta 165 (2015) 45-55.

[43] G. Brug, A. van den Eeden, M. Sluyters-Rehbach, J. Sluyters, The analysis of electrode impedances complicated by the presence of a constant phase element, J. Electroanal. Chem. Interfacial Electrochem. 176 (1) (1984) 275-295.

[44] J. Rezek, I. Klein, J. Yahalom, Structure and corrosion resistance of oxides grown on maraging steel in steam at elevated temperatures, Appl. Surf. Sci. 108 (1) (1997) 159-165.

[45] V. Vignal, S. Ringeval, S. Thiébaut, K. Tabalaiev, C. Dessolin, O. Heintz, F. Herbst, R. Chassagnon, Influence of the microstructure on the corrosion behaviour of lowcarbon martensitic stainless steel after tempering treatment, Corros. Sci. 85 (2014) 42-51.

[46] S. Harvey, P. Marsh, W. Gerberich, Atomic force microscopy and modeling of fatigue crack initiation in metals, Acta Metall. Mater. 42 (10) (1994) 3493-3502.

[47] W. Gerberich, S. Harvey, D. Kramer, J. Hoehn, Low and high cycle fatigue - a continuum supported by AFM observations, Acta Mater. 46 (14) (1998) 5007-5021.

[48] D.J. Duquette, Corrosion Fatigue: Chemistry, Mechanics, and Microstructure, Nace2, National Association of Corrosion, 1973.

[49] P.G. Marsh, S.E. Harvey, M.D. Kriese, W.W. Gerberich, Environmental effects on fatigue crack development in HSLA steel and fine grain $\alpha$-Titanium, Scr. Metall. Mater. (1995) 825-829.

[50] R.W. Landgraf, A.M. Sherman, J.W. Sprys, ICM II American Society for Metals, (1978), pp. 512-517. 